\title{
SER OU FAZER-SE PROFESSOR? ANÁLISE DE UMA EXPERIÊNCIA DE FORMAÇÃO CONTINUADA COM PROFESSORES DE CURSOS TÉCNICOS
}

\author{
Ana Sara Castaman* \\ Marilandi Mascarello Vieira** \\ Marizete Bortolanza Spessatto ${ }^{* * *}$
}

Resumo: O presente artigo faz uma reflexão sobre o papel da formação continuada para a atuação pedagógica de docentes com formação inicial fora das licenciaturas. A análise está embasada em uma experiência de formação continuada desenvolvida pelas autoras no ano de 2012, com professores que atuam em um instituto federal de educação, ciência e tecnologia. As reflexões são embasadas em autores como Arroyo (1999, 2000), Freire (2006), Giesta (2005) e André (2005), entre outros. Ainda, discute-se a análise dos depoimentos dos participantes acerca da relevância da formação continuada para sua práxis pedagógica, como facilitadora do processo ensino e aprendizagem. Focaliza a pertinência da formação continuada para docentes que não tiveram a formação pedagógica em sua formação profissional e a contribuição dessa para o processo ensino e aprendizagem.

Palavras-chave: Formação continuada. Ensino e aprendizagem. Cursos técnicos profissionalizantes. 
Abstract: This paper analyzes the role of continuing training in pedagogical performance of professors whose basic professional training is not related to Education. The analysis is based in a continuing training experience promoted by the authors, in 2012, with professors from a Federal Institute of Education, Science and Technology. Bibliographies from Arroyo (1999, 2000), Freire (2006), Giesta (2005) e André (2005), and other ones, support the discussion. Teachers testimonials about the importance of continuing training to their pedagogical praxis, furthering the teaching-learning process, are analyzed and discussed. Moreover, the pertinence of continuing training to professors who were not instructed in Educational subjects is investigated, also its contribution to the teaching-learning process.

Keywords: Continuing training. Teaching-learning. Technical career courses. 


\section{Reflexões iniciais sobre o tema}

A formação continuada de professores tem assumido destaque nos últimos tempos. Basta ver os investimentos feitos pelos governos nessa área, apostando na formação como forma de melhorar os índices de desempenho dos estudantes e a eficiência do processo ensino-aprendizagem ${ }^{1}$. Em uma análise geral, Mizukami (2006) ressalta que a formação continuada, além de outros objetivos, implica em apresentar novas metodologias e colocar os profissionais da educação em um permanente diálogo com as discussões teóricas atuais, para que possam vir a contribuir com as transformações necessárias da ação pedagógica. Arroyo (1999) reforça essa ideia ao aludir à formação pedagógica entre duas dimensões: a de aprender a fazer e o de formação em ação.

Em outras palavras, o professor, ao assumir a docência como profissão, tem o papel de continuar sua formação para ter a capacidade de formar sujeitos com saberes específicos, pensantes, criativos, capazes de lidar com o novo, de mediar conceitos e procedimentos, que lhes permitam elaborar alternativas para os desafios que possam encontrar no mundo pessoal e do trabalho. Ao tratar sobre a formação inicial, Pimenta (2002, p. 17) alerta acerca da necessidade de articular os saberes docentes às suas práticas:

Para além da finalidade de conferir uma habilitação legal ao exercício profissional da docência, do curso de formação inicial se espera que forme o professor. Ou que colabore para sua formação. Melhor seria dizer que colabore para o exercício e sua atividade docente, uma vez que o professorar não é uma atividade burocrática para a qual se adquire conhecimentos e habilidades técnico-mecânicas. Dada a natureza do trabalho docente, que é ensinar 
como contribuição ao processo de humanização dos alunos historicamente situados, espera-se da licenciatura que desenvolva nos alunos conhecimentos e habilidades, atitudes e valores que lhes possibilitem permanentemente irem construindo seus saberes-fazeres docentes a partir das necessidades e desafios que o ensino como prática lhes coloca no cotidiano.

Quanto à formação continuada, se ela é um pré-requisito para todos os professores, ainda mais para aqueles que vêm se tornam professores sem passar pelas licenciaturas na formação inicial. A formação continuada tornou-se legitimada aos profissionais diante os desafios que demandam a sua ação cotidiana, aumentadas pela expansão da educação profissional. Se, por um lado, ela se apresenta como uma alternativa de acesso à educação formal, aliada à formação para o mundo do trabalho, essa expansão levou às salas de aula uma quantidade significativa de profissionais de outras áreas que passam a assumir a docência como profissão. Há que se destacar que a docência no ensino técnico e tecnológico tem sido exercida por profissionais de diversas áreas do conhecimento e com diferentes tempos de dedicação à instituição na qual atuam, sendo que muitos deles nunca tiveram contato com a formação pedagógica sistemática, o que, por si só, gera um desafio à prática pedagógica. Segundo Moura (2008, p. 31):

Esse é um problema estrutural do sistema educacional e da própria sociedade brasileira, pois, enquanto para exercer a medicina ou qualquer outra profissão liberal é necessária a correspondente formação profissional, para exercer o magistério, principalmente o superior ou a denominada educação profissional, não há muito rigor na exigência de formação na correspondente profissão - a de professor. 
Estudos apontam que quando o profissional não tem formação pedagógica, geralmente, a sua práxis reflete a postura dos professores que atuaram na sua formação: é a chamada "formação mimética" (GUEDES, 2006). Diferente do que ocorre em outras profissões, destaca Guedes, espera-se do professor a experiência profissional adquirida "por contágio":

[...] a prática das escolas não costuma distinguir entre professores experientes e iniciantes: empurram todos para dentro da sala de aula e, metaforicamente, trancam a porta por fora, como se fosse apenas a mínima obrigação também dos estreantes saírem-se bem já nesse primeiro contato com o aluno. Espera-se deles que já saibam como se comportar, o que, na prática, significa que se espera que tenham discernimento para aproveitar a experiência que adquiriam do contato que tiveram com toda a gama de modelos ao longo de sua vida de alunos. (GUEDES, 2006, p. 26).

Dessa forma, ou os professores tornam-se autodidatas e superam dificuldades a partir do entusiasmo e/ou por erros e acertos, ou buscam a preparação pedagógica quando se deparam com eventos desafiadores no cotidiano escolar.

Tendo em vista os desafios que perpassam à formação de professores, as instituições têm organizado processos de formação continuada para aqueles docentes que, em seus cursos de graduação, não tiveram as disciplinas pedagógicas, bem como o estágio de docência. Muitas vezes, quando não são as instituições que oportunizam esse processo, são os próprios docentes que procuram pela formação. Assim se deu o caso em análise neste artigo. Com o objetivo de oportunizar conhecimentos pedagógicos à formação profissional docente, o curso de Pedagogia e o Núcleo de Apoio Psicopedagógico e Educacional (NAPSE), do Instituto 
Federal do interior do Estado de Santa Catarina, promoveram a Formação Continuada em Metodologias de Ensino e Aprendizagem aos docentes dos cursos técnicos em Segurança do Trabalho e Eletroeletrônica, a partir de uma demanda levantada pelos professores. O que se observou ao longo do processo (fevereiro a julho de 2012), e será relatado ao longo deste texto, é que o curso permitiu o conhecimento e a vivência de estratégias de atuação docente, com o intuito de contribuir tanto com a segurança dos professores em sala de aula quanto a melhoria do processo de ensino e aprendizagem.

O objetivo do curso de formação continuada foi de que os docentes entendessem os processos de ensino e aprendizagem, suas características, bem como as suas implicações para a prática docente. Nessa esteira, propôs-se discutir os componentes do plano de ensino; as regras básicas para elaboração de instrumentos de avaliação e a articulação desta com os objetivos de cada componente curricular; identificar as estratégias de ensino e selecionar as mais compatíveis com a disciplina e objetivos a alcançar; refletir sobre as principais concepções de aprendizagem, relacionando-as às estratégias de ensino e à avaliação.

Na primeira parte deste texto apresenta-se a metodologia empregada, após analisa-se a importância da formação continuada para docentes em cursos técnicos e, por fim, como a formação continuada pode facilitar o processo ensino e aprendizagem.

\section{Formação continuada: a experiência em análise}

A formação continuada aqui em análise foi realizada no primeiro semestre de 2012 em um instituto federal do interior de 
Santa Catarina, Brasil. A instituição iniciou suas atividades em março de 2006, como extensão de uma escola agrotécnica federal, com o ingresso da primeira turma do Curso de Educação Profissional Técnica de Nível Médio em Agropecuária. Em 2009, começaram as atividades com estudantes nos cursos de Eletroeletrônica e Informática e, em 2010, houve o ingresso dos alunos no Curso Técnico em Segurança do Trabalho. A oferta de cursos de graduação iniciou em 2011, com Ciência da Computação e, em 2012, foi implantado o curso de Pedagogia.

A instituição possuía, até agosto de 2012, 12 cursos regulares, sendo seis técnicos nas modalidades integrado, subsequente e concomitante, três cursos superiores e três cursos de pós-graduação em nível de especialização totalizando 34 turmas, com 1.268 estudantes matriculados, 61 docentes e 57 técnico-administrativos.

O curso de formação aqui em análise foi organizado em encontros mensais que totalizaram 40 horas. As reflexões basearam-se no estudo dos temas indicados para cada etapa da formação, os quais foram precedidos pela leitura de textos-base, realizada a distância e da discussão entre os envolvidos. Outra estratégia utilizada foram os seminários que ficaram sob responsabilidade de cada participante e a elaboração e análise dos planos de ensino e dos instrumentos de avaliação.

As temáticas abordadas foram planejamento do processo ensino-aprendizagem: a organização dos planos de ensino, orientações para elaboração de instrumentos de avaliação, estratégias de ensino-aprendizagem e concepções de aprendizagem.

Os participantes foram oito docentes dos cursos técnicos em Segurança do Trabalho e de Eletroeletrônica contratados em regime integral, de dedicação exclusiva, com formação profissional na área das engenharias e com idade entre 25 a 32 anos, vivenciando suas primeiras experiências como docentes. 
Também fizeram parte do grupo três técnicas para assuntos educacionais, com vínculo contratual de 40 horas, com formação em cursos de licenciatura e idade entre 25 a 40 anos que atuam como equipe de apoio aos docentes e estudantes dos cursos envolvidos na formação. Os fragmentos analisados no presente artigo provêm de depoimentos colhidos durante o processo reflexivo de formação continuada.

\section{A formação continuada para docentes de cursos técnicos}

Atualmente, a educação profissional brasileira evidencia o imperativo de reestruturação, articulando teoria e prática, o científico e o tecnológico, com informações e conhecimentos que possibilitem aos professores complementar com o espírito crítico e de forma criativa o seu desempenho em sala de aula. Para Giesta (2005, p. 412): "Ensinar, hoje, exige desenvolvimento de habilidades de comunicação, raciocínio, criticidade e criatividade, que não fiquem apenas nas intenções, mas que sejam calcadas no desenvolvimento contínuo e isso passa pela atualização dos saberes."

Machado (2008, p. 15) corrobora acerca da formação de professores de educação profissional na atualidade:

Os professores de educação profissional enfrentam novos desafios relacionados às mudanças organizacionais que afetam as relações profissionais, aos efeitos das inovações tecnológicas sobre as atividades de trabalho e culturas profissionais, ao novo papel que os sistemas simbólicos desempenham na estruturação do mundo do trabalho, ao aumento das exigências de qualidade na produção e nos serviços, à exigência de maior atenção à justiça social, às questões éticas e de sustentabilidade ambiental. 
São novas demandas à construção e reconstrução dos saberes e conhecimentos fundamentais à análise, reflexão e intervenções críticas e criativas na atividade de trabalho.

Considerando os fatores citados por Machado (2008) e aqueles que nos movem nesta breve reflexão, avalia-se que a formação continuada deve assegurar aos docentes reflexões teóricas e práticas que auxiliem na formação dos alunos, na articulação das estruturas curriculares dos cursos técnicos em que atuam, de modo que os conteúdos sejam atualizados e contextualizados a partir da realidade local e dos discentes. Conforme Giesta (2005, p. 411): "A aquisição de informações fragmentadas e dirigidas para a prática minimiza a ação intelectual do professor." Conclui a autora que a confiança do docente em reconhecer-se apto a entender e analisar as políticas, procedimentos, resultados, estudos, propostas educacionais "inerentes à sua profissão e qualificação alavanca sua identidade profissional” (GIESTA, 2005, p. 411) e, como consequência, esse docente também se compromete com sua formação inicial e continuada.

Desse modo, como responsáveis pelo curso de formação continuada aqui em análise, organizamos os encontros pautados nas demandas advindas do cotidiano da sala de aula, para que a formação se estruturasse em uma proposta que contemplasse as intenções e a atuação dos docentes em seus estudos e disciplinas. Almejou-se durante o curso de formação vislumbrar no conjunto das interações com os docentes ações que facilitassem a conexão curricular à realidade local dos alunos.

No primeiro encontro, os docentes foram ouvidos sobre as dificuldades encontradas em sala de aula. Os professores haviam ingressado na instituição recentemente, sendo essa a primeira experiência na docência. Iniciavam o exercício da profissão docente, 
portanto, sem a salvaguarda da formação que lhe assegurasse a identidade como professor, o "ofício de mestre", como menciona Miguel Arroyo (2000, p. 25): "Uso a expressão 'ofício de mestre' para chamar a atenção para essa longa história, para procurar nossa identidade longe, para nos ver como uma construção social, histórica, cultural que finca raízes profundas no passado.”

Os participantes compartilharam angústias, necessidades e expectativas:

Nunca havia estado em uma sala de aula, às vezes tenho dificuldade em mediar os conteúdos aos alunos. Não sei que linguagem utilizar, técnicas, etc. (Professor A)².

Tenho uma formação técnica, o que dificulta formar na perspectiva humanística e instrumentalizar os alunos também para serem autônomos e cidadãos. (Professor B).

Precisamos de formação continuada, porque nas engenharias não há disciplinas pedagógicas, didáticas, o que não nos fortalece como docentes. Necessitamos aprender metodologias que facilitem o processo ensino e aprendizagem e aproximem o conteúdo à realidade dos alunos. (Professor C).

Eu tive formação continuada em outro local que atuei, mas sinto a necessidade de cursos de formação. Meus colegas estão sempre reclamando da dificuldade para compreender os anseios dos discentes e em conseguir fazer com que a aula seja prazerosa para ambos. (Professor D).

Participei de um treinamento em 2010 e foi extremamente tradicional porque não articulou a teoria e a prática. (Professor F).

Foi extremamente importante realizar essa escuta atenta e aberta dos relatos dos docentes, captando seus valores, expectati- 
vas, dificuldades e limites, pois esses foram elementos balizadores da atividade à medida que se considerou que uma ação formadora precisa tomar como ponto de partida o que os profissionais já elaboraram sobre o processo ensino-aprendizagem, porque são eles os sujeitos da atividade formativa. Considera-se, também, o que afirma Sacristan (1999, p. 83):

As primeiras experiências são fundamentais, porque a partir delas, o habitus, como ocorre com as instituições, tende a assegurar sua própria sobrevivência [....]. Sempre se destacou o valor decisivo das primeiras experiências dos professores para explicar seus estilos docentes rapidamente estabilizados.

A proposição do curso de formação continuada, assim, buscou atender as demandas do grupo, articulando a teoria com a prática porque se partiu da premissa de que, embora fosse importante iniciar a inserção do grupo nas discussões de cunho teórico da área da educação, isso não era prioritário naquele momento se elas não possibilitassem aos professores relacioná-las com as situações vivenciadas no cotidiano da sala de aula. Faz-se a afirmação por considerar-se que a formação continuada precisa responder às demandas dos sujeitos participantes, constituindo-se num espaço de busca por novos saberes, mas também de troca de experiências que lhes permita construir suas competências como educadores.

Compartilha-se, assim, da concepção de formação proposta por Silva (2000) que entende que ela envolve dois polos distintos: o de saber, que se articula à dimensão global do sujeito, e o segundo, o saber fazer, que está ligado à exigência de saberes e competências especializadas. São, porém, duas dimensões de um único processo e, portanto, profundamente articulados, pois o segundo 
polo orienta e redimensiona o primeiro, à medida que favorece a autorreflexão e a análise que resultam na desconstrução e na reestruturação do sujeito aprendente. A formação de professores permite aos docentes "[...] a capacidade de transformar em experiência significativa os acontecimentos que geralmente acontecem no quotidiano, tendo como horizonte um projecto pessoal e coletivo." (RANJARD, 1989 apud GARCÍA, 1997, p. 20).

Freire (2006, p. 39) também ressalta que, na formação permanente dos professores, o fundamental é a reflexão crítica sobre a prática que "[...] tem de ser de tal modo concreta que quase se confunda com a prática." O autor complementa que todo o processo de formação deve fazer sentido para o fazer educativo, para a humanização e deve se voltar para o exercício cotidiano, na prática vivida. Ao avaliar sua atuação, o docente poderá compreender como estão articuladas as suas aulas com os demais processos educativos presentes na vida dos alunos, implica em entender o sujeito como um ser da práxis.

No caso aqui em análise, os professores foram participativos e colaborativos durante todo o curso, sendo interlocutores do processo e formação. Esse é, segundo Machado (2008), um dos pressupostos básicos para o docente da educação profissional, que é ser essencialmente "[...] um sujeito da reflexão e da pesquisa, aberto ao trabalho coletivo e à ação crítica e cooperativa, comprometido com sua atualização permanente na área da formação específica e pedagógica." (MACHADO, 2008, p. 17).

Os professores em formação buscaram exercitar as habilidades docentes em atividades como elaboração de planos de ensino e de instrumentos de avaliação, estudo, aplicação em sala de aula e relato de metodologias e técnicas de ensino - cada participan- 
te socializou com o grupo e dele recebeu avaliação e sugestões -; mostraram sua capacidade de reflexão, reconhecendo o lugar decisivo e formativo do docente como agente de transformação dos sujeitos. A reflexão remete à citação de Freire (2006, p. 22): "Ensinar não é transferir conhecimento, mas criar as possibilidades para a sua produção ou a sua reconstrução.”

Os encontros mensais de discussão, seguidos por tarefas de internalização dos saberes adquiridos no curso ao cotidiano da ação docente, proporcionaram o encadeamento interativo de momentos de formação e de trabalho, o que promoveu um processo permanente de mobilização em torno dos saberes: dos adquiridos no curso e levados ao trabalho e esses ajudaram a ressignificar as práticas e corroborar ou negar as proposições do processo de formação.

Conforme Fullan e Hargreaves (2000), Giesta (2005) e Freire (2006), confia-se à educação a formação de um cidadão crítico, reflexivo e transformador de sua realidade; entende-se que a formação continuada de professores deve capacitar os docentes para a mediação de conhecimentos e para práticas reflexivas de sua atuação. Freire (2006, p. 39) pontua que a formação permanente dos professores tem como eixo fundamental a reflexão crítica sobre a prática que "[...] tem de ser de tal modo concreta que quase se confunda com a prática."

Ao refletir sob sua atuação, o docente poderá verificar como as suas aulas estão articuladas com os demais processos educativos presentes na vida dos alunos. Corrêa (2005, p. 133) traz considerações sobre o processo de reconhecimento da atuação docente, enquanto um fator pertinente para a mediação em sala de aula. 
Ao se tentar reconhecer os movimentos que permitiram e possibilitam a existência destas sociedades, o professor tenderá a reconhecer cada vez mais, e com maior organizacidade, que suas ações estão articuladas com outros processos educativos, desenvolvidos por outros agentes educadores na sociedade para além da escola, o que, de certa forma, se transformará em novas inquietações e renovados desafios para a instituição escolar. (CORRÊA, 2005, p. 133).

Vislumbramos nos excerto das falas dos participantes do curso reflexões sobre o cotidiano escolar, a realidade dos alunos e a participação coletiva e cooperativa na percepção da realidade e no auxílio do processo ensino e aprendizagem.

Precisamos cada vez mais trazer as empresas para o espaço escolar. Convidá-los para participar na produção dos nossos projetos pedagógicos. Assim, também vamos formar alunos focados para o que o mercado local, regional ou mesmo global, espera. (Professor D).

As empresas devem ser nosso foco, ou seja, se formamos profissionais para atuar no mercado ${ }^{3}$, precisamos saber as exigências dele. (Professor F).

Os comentários explicitam a complexidade da formação continuada, pois ela se desenvolve em contextos determinados, mas singulares, porque carregados de conflitos de valores que emergem da visão de mundo de capa participantes: educar para o mercado/mundo do trabalho? Ou para a transformação social? Qual a concepção de homem que norteia o trabalho: a lógica da globalização econômica ou a formação de sujeitos autônomos e críticos? Essas são questões que ultrapassam a discussão pedagógica porque envolvem ações éticas e políticas.

A formação pedagógica permitiu aos docentes a reflexão acerca da sua formação, do curso em que atuam, especialmente, nos 
aspectos em que podem melhorar. Destacou-se para a participação da comunidade como um dos elementos para auxiliar os docentes na aproximação dos conteúdos à realidade concreta dos alunos.

\section{A formação continuada como facilitadora do processo ensino e aprendizagem}

Admitir a formação continuada dos docentes como facilitadora do processo ensino e aprendizagem implica em um processo reflexivo que abarque os objetivos desse processo, novas metodologias de ensino e auxilie na construção de saberes e sentidos para a organização do cotidiano escolar.

André (2005, p. 15) faz considerações sobre como a dimensão reflexiva exerce um novo olhar sobre o cotidiano escolar.

Colocar uma lente de aumento na dinâmica das relações e interações que constituem o seu dia-a-dia, aprendendo as forças que a impulsionam ou retém, identificando as estruturas de poder e a atuação de cada sujeito nesse complexo inter-relacional em que as ações são - ou - não implementadas e relações são estabelecidas e modificadas.

Giesta (2005, p. 38), em sua pesquisa sobre o cotidiano escolar e a formação reflexiva, avigora a relevância de um processo reflexivo para a construção de saberes a partir de uma atitude consciente, deliberada e organizada.

O compromisso com esse papel envolve-o num processo coletivo de reflexão e construção de uma atitude consciente, deliberada e organizada da valorização das situações do trabalho escolar. Isso, no entanto, não pode depender da implantação de um modelo pedagógico externo, ao qual 
o professor se conforme ou resista. A adoção de uma atitude crítico-reflexiva nas situações reais vividas na escola, certamente exigirá dele análise objetiva, bem como, avaliação contínua das formas e conseqüências de sua intervenção pedagógica - individual e coletiva. (GIESTA, 2005, p. 38, grifos do autor).

Entendemos que o curso de formação continuada facilitou o processo ensino e aprendizagem, a partir dos testemunhos colhidos no decorrer da atividade, uma vez que foi considerado aplicativo e serviu de base para os docentes durante as aulas ministradas no semestre.

Foi um curso super prático e não segmentado, no qual estávamos envolvidos em todo o processo. Isso facilitou a interação com o conteúdo. Sugiro que os demais professores da instituição possam participar. Ainda, acho que poderíamos dar continuidade a essa formação com outras temáticas. (Professor A).

Os temas abordados foram atuais, eleitos por nós e, em especial, foram trabalhados de maneira prática. Essa práxis facilita as nossas ações em sala de aula, porque a todo momentos estávamos intercambiando o que aprendemos aqui com o espaço da sala de aula. (Professor C).

O curso de formação de professores que foi realizado de forma continuada durante todo o primeiro semestre de 2012 e consolidou no âmbito teórico e prático as abordagens e estratégias de ensino. Foi possível socializar experiências vividas, compartilhando dificuldades que enfrentamos na prática em sala de aula e aprimoramos nossas aulas. Discutindo com o grupo descobrimos formas mais interessantes de trabalhar. (Professor E).

Eu gostei muito desse curso, porque ele foi realizado durante o semestre inteiro e não apenas em um final de semana. Assim, pude ir aplicando as técnicas aprendidas, 
trazendo essa vivência para o grupo e levando alternativas, ideias para melhorar ainda mais as aulas. Aos poucos fomos reinventando as nossas aulas. (Professor F).

Verifica-se nos depoimentos dos docentes que o espaço de formação permitiu aprender estratégias para a prática pedagógica, mas superou essa ação em virtude de desafiar para reflexões que surgiram da troca de saberes que favoreceu a releitura da experiência. Quando indagados pelos colegas nos relatos das atividades realizadas em sala de aula, quando solicitavam esclarecimentos sobre os textos estudados, quando demandavam mais explicações do porquê se agiu dessa ou daquela maneira na condução da aula, notou-se que se constituíam em grandes oportunidades para a reflexão.

A formação continuada serve como qualificação profissional e encontro de discussões pedagógicas que (re)dimensionam conceitos na formação docente. Ainda, afirma-se a partir dos excertos dos professores em formação que há uma necessidade nos institutos federais de aperfeiçoamento profissional constante, seja ele mediado a partir de cursos de formação continuada, seja ele de pós-graduação, para o pleno exercício do magistério. Reitera-se que a formação do professor não se encerra ao sair da formação inicial na universidade, mas deve ocorrer de modo dinâmico e interativo por todo o período em que a docência é exercida.

\section{Reflexões finais: o que ainda há por ser feito}

Este breve artigo relata alguns resultados do esforço de um grupo de professores em entender e analisar o processo de formação continuada enquanto uma política pública para a melhoria 
da qualidade de ensino oferecida pela rede federal. Tardif (2000, p. 8) ressalta que "[...] cada vez mais os estudos sobre os saberes docentes vêm se constituindo como possibilidade de análise de processos de formação e profissionalização dos professores." Os profissionais compreendem que é pertinente a continuidade dessa formação para que possam contribuir e reconstruir suas práticas e concepções de educação.

Conclui-se que a formação continuada constitui-se como uma atividade desafiadora para as instituições de ensino e, tratando-se da formação pedagógica de profissionais de outras áreas que não as licenciaturas, a tarefa remete a um duplo desafio, uma vez que a crença de que o profissional que domina um ofício pode ensiná-lo está arraigada na educação profissional.

A atividade desenvolvida ratificou a necessidade de o docente dominar um conjunto de habilidades que excedem o saber fazer e o grupo de docentes que protagonizou a presente experiência corrobora essa afirmação ao valorizar o seu fazer cotidiano como profissional da educação. Os docentes assumiram as tarefas propostas no curso de formação continuada, comprometendo-se com o processo porque perceberam-se aptos a compreender e analisar as políticas, procedimentos, resultados, estudos, propostas educacionais "[...] inerentes à sua profissão e qualificação que alavanca sua identidade profissional." (GIESTA, 2005, p. 411).

Os participantes confirmaram a constante necessidade de qualificação profissional do professor para que possa entender as mudanças paradigmáticas que assolam o contexto escolar e interferem na qualidade da educação.

As reflexões críticas e colaborativas surgidas durante o curso de formação pedagógica indicam que a formação continuada é 
um processo ao mesmo tempo individual e coletivo de construção pessoal e profissional a partir de uma apropriação crítica da discussão teórica realiza, mas articulada à prática experienciada, que ecoou no fazer cotidiano. Assim, os conhecimentos construídos no exercício profissional pelos docentes serviram de base para (re)significar teorias, tornando-as relevantes à sua prática, o que aponta que é necessário, cada vez mais, valorizar os saberes que os docentes vão adquirindo por meio da reflexão acerca de suas práticas ligadas ao ensino e ao universo do trabalho.

\section{Referências}

ANDRÉ, M. E. D. A. A prática escolar na escola de $1^{\circ}$ grau. In: VÁRIOS AUTORES. Desafio para a Didática. São Paulo: Edições Loyola, 2005.

ARROYO, Miguel G. Ciclos do Desenvolvimento Humano e formação de professores. Revista Educação e Sociedade, Campinas, n. 68, p. 143$162,1999$.

2000.

. Ofício de mestre: imagens e auto-imagens. Petrópolis: Vozes,

BUARQUE, Cristovam. A universidade numa encruzilhada. In: UNESCO. Educação superior: reforma, mudança e internacionalização. Paris: UNESCO, 2003.

CORRÊA, Vera. As relações sociais na escola e a produção da existência do professor. In: FRIGOTTO, Gaudêncio; CIAVATTA, Maria; RAMOS, Marise (Orgs.). Ensino Médio integrado: concepções e contradições. São Paulo: Cortez, 2005. p. 128-147.

FREIRE, Paulo. Pedagogia da Autonomia: saberes necessários à prática educativa. 34. ed. São Paulo: Paz e Terra, 2006. 
FULLAN, Michel; HARGREAVES, Andy. A escola como organização aprendente: buscando uma educação de qualidade. 2. ed. Porto Alegre: Artes Médicas, 2000.

GARCÍA, Carlos Marcelo. A formação de professores: novas perspectivas baseadas na investigação sobre o pensamento do professor. In: NÓVOA, António. Os professores e sua formação. Lisboa: Dom Quixote, 1997.

GIESTA, Nágila C. Cotidiano escolar e formação reflexiva do professor: moda ou valorização do saber docente? Araraquara: JM, 2005.

GUEDES, P. C. A formação do professor de português: que língua vamos ensinar? São Paulo: Parábola Editorial, 2006.

MACHADO, Lucília Regina de Souza. Diferenciais inovadores na formação de professores para a educação profissional. Revista Brasileira da Educação Profissional e Tecnológica - Ministério da Educação, Secretaria de Educação Profissional e Tecnológica. Brasília: MEC, SETEC, v. 1, n. 1, jun. 2008.

MIZUKAMI, M. G. N. Aprendizagem da docência: professores formadores. Revista E-Curriculum, São Paulo, v. 1, n. 1, dez./jul. 20052006.

MOURA, Dante Henrique. A formação de docentes para a educação profissional e tecnológica. Revista Brasileira da Educação Profissional e Tecnológica - Ministério da Educação, Secretaria de Educação Profissional e Tecnológica. Brasília: MEC, SETEC, v. 1, n. 1, jun. 2008.

PIMENTA, Selma Garrido. Saberes pedagógicos e atividade docente. São Paulo: Cortez, 2002.

SACRISTAN, José Gimeno. Poderes instáveis em educação. Porto Alegre: Artes Médicas, 1999.

SILVA, Rinalva. Educação: a outra qualidade. Piracicaba: Unimep, 2000.

TARDIF, Maurice. A ambiguidade do saber docente nas reformas relativas à formação universitária para o magistério. 2000. (Texto digitado). 


\section{Notas}

* Graduada em Psicologia e Pedagogia. Especialista em Mídias na Educação. Mestre em Educação nas Ciências. Doutora em Educação. Docente no Instituto Federal de Educação, Ciência e Tecnologia do Rio Grande do Sul, campus Sertão. E-mail: <anacastaman@hotmail.com>.

${ }^{*}$ Graduada em Pedagogia, História e Direito. Mestre em Educação e mestre em Direito. Docente no Instituto Federal de Educação, Ciência e Tecnologia do Rio Grande do Sul, campus Sertão. E-mail: <marilandi.vieira@sertao.ifrs.edu.br>.

*** Graduada em Pedagogia. Mestre em Linguística. Doutora em Educação. Docente no Instituto Federal de Educação, Ciência e Tecnologia Catarinense, campus Videira. E-mail: <marizete.spessato@ifc-videira.edu.br>.

${ }^{1}$ Um exemplo é o Pacto Nacional pela Alfabetização na Idade Certa, lançado pelo Governo Federal em julho de 2012 e que, entre as ações, prevê a formação continuada de professores alfabetizadores de todo o país.

${ }^{2}$ Para preservar a identidade dos professores, a identificação dos diferentes sujeitos seguirá a ordem alfabética.

${ }^{3}$ Não fazemos nenhuma reflexão acerca do uso do termo "mercado de trabalho", em substituição a "mundo do trabalho", por não ser este o foco do presente artigo. 
